\title{
PERANCANGAN SOP (Standar Operating Procedure) PROSES PRODUKSI AMPLANG DI SENTRA INDUSTRI KECIL HASIL PERTANIAN DAN KELAUTAN (SIKHPK) TERITIP, BALIKPAPAN
}

\author{
Standar Operating Procedure (SOP) of Amplang Production in Center \\ of Small Fisheries and Marine Products Industry (SIKHPK) Teritip, \\ Balikpapan
}

\author{
Nia Ariani Putri' ${ }^{1}$, Zulfatun Najah ${ }^{1)}$, Zulmaneri' ${ }^{2)}$, Taufik Hidayat ${ }^{3}$ ) \\ 1)Program Studi Teknologi Pangan, Fakultas Pertanian, Universitas Sultan Ageng Tirtayasa \\ ${ }^{2}$ Program Studi Agribisnis, Fakultas Sains dan Teknologi, UIN Syarif Hidayatullah Jakarta \\ 3) Pusat Teknologi Agroindustri, Kedeputian TAB, Laptiab Puspiptek Serpong \\ Email: nia.ariani@untirta.ac.id
}

\begin{abstract}
ABSTRAK
Dalam rangka menggerakkan roda perekonomian nasional, pemberdayaan Industri Kecil Menengah (IKM) dinilai menjadi salah satu solusi yang tepat. Dengan adanya IKM mengakibatkan terjadinya peningkatan penyerapan tenaga kerja sehingga mampu menekan angka pengangguran. Pendekatan kelompok juga dinilai sebagai salah satu pilihan yang lebih baik dalam pengembangan IKM yaitu dalam bentuk sentra IKM. Sentra Industri Kecil Hasil Pertanian Dan Kelautan (SIKHPK) Teritip merupakan salah satu sentra IKM yang terletak di Kalimantan, tepatnya di Kota Balikpapan yang memanfaatkan hasil pertanian dan hasil perikanan khususnya untuk diolah menjadi suatu produk, salah satu contohnya yaitu amplang. Amplang merupakan makanan menyerupai kerupuk yang terbuat dari ikan. Proses produksi amplang meliputi proses persiapan bahan baku, pencampuran bahan, pencetakan, penggorengan, penirisan, dan pengemasan. Untuk menghasilkan produk amplang yang seragam dan dapat bersaing dengan produk sejenis di pasar, maka dibutuhkan SOP proses prduksi amplang untuk menjamin mutu produk amplang yang dihasilkan. SOP dirancang menggunakan swimlane flowchart. Dalam proses produksinya, dibagi menjadi beberapa bagian yaitu bagian penerimaan bahan, produksi, pengemasan dan pemasaran yang masing-masing bagian mempunyai tugas masing-masing.
\end{abstract}

Kata kunci: Sentra IKM, hasil perikanan, amplang, SOP.

\begin{abstract}
In order to drive the wheels of the national economy, empowerment of Small and Medium Enterprise (SME) is considered to be one of the right solutions. With the existence of the SME resulting in an increase in employment so that it can reduce unemployment. The group approach is also considered as one of the better choices in the development of SME, namely in the form of SME centers. Teritip Agricultural and Marine SmallScale Industry Centers (SIKHPK) is one of the SEM centers located in Kalimantan, precisely in Balikpapan City that uses agricultural products and fisheries products specifically to be processed into a product, one example of which is amplang. Amplang is a food resembling crackers made from fish. The amplang production process includes the process of raw material preparation, material mixing, printing, frying, slicing, and packaging. To produce a same envelope product that can compete with similar products on the market, an SOP for the amplang production process is needed to ensure the quality of the amplang products produced. SOP is designed using swimlane flowchart. In the production process, it is divided into several parts, namely the acceptance of materials, production, packaging and marketing, each of which has their respective duties.
\end{abstract}

Key words: SEM center, fisheries product, amplang, SOP.

Jurnal JITIPARI Vol. 4 No. 2 Th. 2019: 57-64 


\section{PENDAHULUAN}

Paradigma pembagunan sekarang telah beralih yang awalnya berorientasi pada pertumbuhan ekonomi berskala besar menjadi pembangunan ekonomi yang lebih ditekankan pada ekonomi kerakyatan yaitu Industri Kecil Menengah (IKM). Pemberdayaan Industri Kecil Menengah (IKM) terbukti mampu menjadi roda penggerak perekonomian nasional. Hal tersebut dapat dilihat dari meningkatnya tingkat penyerapan tenaga kerja, sehingga dapat menekan angka pengangguran dan kemiskinan. Hal tersebut sesuai dengan penelitian yang dilakukan oleh Dongoran, F.R., Nisa, K., Sihombing, M., \& Pueba, L.D., (2016), hasil penelitian menunjukkan bahwa dengan adanya Usaha Mikro Kecil Menengah (UMKM) mampu menyerap tenaga kerja sehingga mengurangi tingkat pengangguran terbuka di kota Medan. Oleh karena itu, pemberdayaan dan pengembangan IKM sangat dibutuhkan tidak hanya untuk meningkatkan kuantitas atau jumlahnya, melainkan juga dalam hal peningkatan kualitas dan daya saing produknya.

Salah satu pendekatan dalam pengembangan IKM yang dinilai berhasil yaitu dengan cara pendekatan kelompok. Pengembangan IKM dengan menggunakan pendekatan kelompok dinilai lebih baik, sebab pendekatan secara individual biasanya tidak mampu menangkap peluang pasar. Selain itu, pendekatan kelompok dinilai dapat membentuk jaringan bisnis yang lebih efektif meningkatkan daya saing usaha sebab dapat saling bersinergi. Pengembangan IKM dalam kelompok mampu meningkatkan kapasitas daya saing usaha IKM, mengoptimalkan potensi sumber daya manusia dan sumber daya alam setempat, memperluas kesempatan kerja, dan meningkatkan produktivitas serta nilai tambah IKM. Berdasarkan Peraturan Menteri Perindustrian Republik Indonesia No. o9/M-IND/PER/2/2016, sentra IKM merupakan kelompok IKM dalam satu lokasi atau tempat yang menggunakan bahan baku menghasilkan produk sejenis dan atau melakukan proses produksi yang sama.

Pembentukan sentra IKM bertujuan untuk memberikan edukasi kepada pelaku industri berproduksi pada tempat yang sesuai dengan standar Good Manufacturing Practice (GMP) dan Sanitation Standard Operating Procedure (SSOP), sehingga akan menjadi lebih mudah untuk menerapkan Hazard Analysis Critical Control Point (HACCP) pada setiap proses produksi. Dalam rangka percepatan penyebaran dan pemerataan industri ke seluruh wilayah Indonesia, hingga saat ini telah dibangun sebanyak 62 sentra IKM baru di Indonesia, salah satunya yaitu Sentra Industri Kecil Hasil Pertanian Dan Kelautan (SIKHPK) Teritip, Balikpapan. SIKHPK merupakan salah satu sentra percontohan dari 4 sentra di wilayah Sumatra dan Kalimantan. SIKHPK memproduksi dan mengembangkan produk dalam sektor perikanan, pertanian dan kerjinan. Produk amplang merupakan salah satu produk unggulan hasil perikanan yang banyak diproduksi dan dijual.

Amplang merupakan kerupuk atau camilan khas Kalimantan yang terbuat dari ikan. Sama seperti kerupuk ikan lainnya, amplang memiliki rasa ikan kental dan gurih (Afifah, 2016). Menurut Alfisyahrica (2015), amplang dibuat dengan mencampurkan ikan dengan tapioka, telur, dan bumbu-bumbu lainnya. Amplang sangat mudah ditemui di seluruh Kalimantan dengan berbagai macam nama seperti kerupuk kuku macan di Balikpapan dan Samarinda. Pada saat ini, sentra IKM belum memiliki SOP proses produksi sehingga dalam memproduksi amplang hanya berdasarkan instruksi dan kebiasaan (tata cara pembuatan amplang) yang digunakan sehari-hari. Menurut Tambunan (2011), SOP adalah pedoman prosedur-prosedur operasional standar yang ada di dalam suatu organisasi (perusahaan) maupun industri dan digunakan untuk memastikan bahwa segala aspek (keputusan, tindakan maupun penggunaan fasilitas) dilakukan secara efisien, efektif, konsisten, standar dan sistematis.

Selain itu, SOP juga dibutuhkan sebagai salah satu persyaratan pemenuhan dokumen penerapan ISO 9000:2008. SOP juga berfungsi untuk mengurangi cacat produk yang dihasilkan serta sebagai pedoman untuk para pekerja atau karyawan dalam melakukan pekerjaannya. Semuanya dilakukan bertujuan untuk 
menghasilkan produk dengan mutu baik dan seragam, dapat diterima konsumen, dan dapat bersaing dengan produk yang lain. Berdasarkan hal tersebut, maka perlu dilakukan penelitian mengenai perancangan SOP pada proses produksi amplang.

\section{METODE PENELITIAN}

\section{a. Rancangan Penelitian}

Penelitian dilaksanakan dengan cara survei pada beberapa IKM penghasil amplang di Kota Balikpapan selama satu bulan. Sebagai salah satu upaya penguatan IKM pengolahan hasil perikanan maka dibangun SIKHPK di Kota Balikpapan. Teknik pengumpulan data untuk objek penelitian dialkukan dengan menggunakan purposive sampling yang bersifat snowball (Irawati dan Hardiastuti, 2016). Purposive sampling adalah teknik pengambilan data yang didasarkan dengan pertimbangan tertentu, dan pengumpulan data dengan intensive interview harus dilakukan melalui wawancara mendalam dari satu responden bergulir ke responden lain yang memenuhi kriteria sampai mengalami titik jenuh (snowball) (Sugiyono, 2014). Rancangan penelitian ditunjukkan pada Gambar 1.

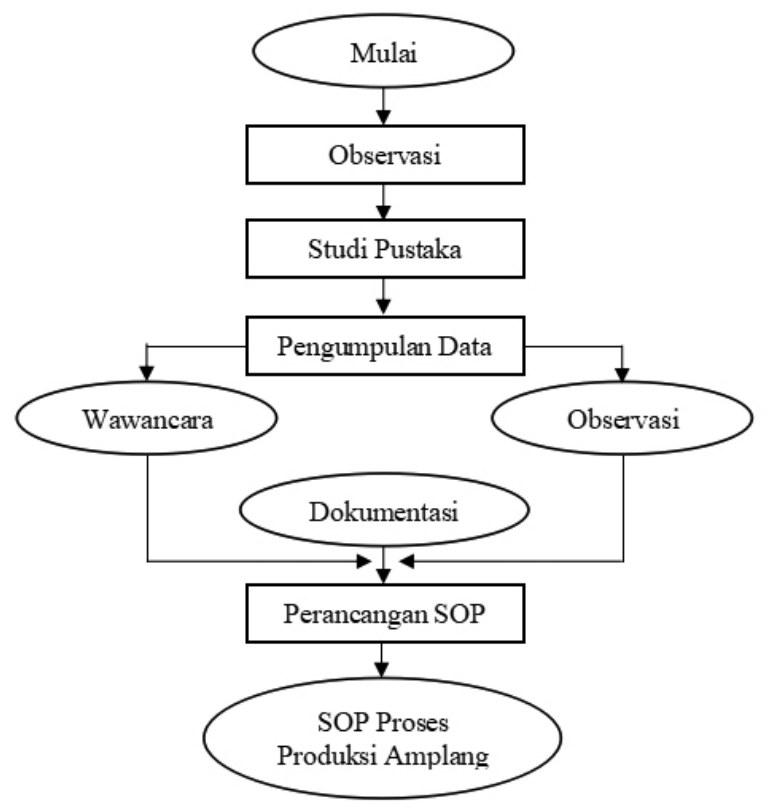

Gambar 1. Rancangan penelitian
Penelitian ini diawali dengan melakukan observasi di SIKHPK. Pada tahap ini, peneliti melakukan observasi dan wawancara mengenai SIKHPK yang di dalamnya terdapat beberapa IKM meliputi proses produksi amplang. Tahap selanjutnya yaitu tahap kajian teori dimana peneliti mempelajari teori-teori terkait penelitian yang akan dilakukan serta hasil penelitian terdahulu. Setelah itu, dilanjutkan dengan pengumpulan data menggunakan tiga metode, yaitu: wawancara, dokumentasi, dan observasi. Terakhir, perancangan SOP menggunakan swimlane flowchart. Swimlane menunjukkan diagram aktivitas untuk menunjukkan siapa melakukan apa (Hendini, 2016).

b. Teknik Pengumpulan Data (Irawati dan Hardiastuti, 2016)

- Observasi

Observasi merupakan suatu teknik pengumpulan data-data dengan melakukan pengamatan secara langsung ke lapangan.

- Wawancara

Wawancara merupakan teknik pengumpulan data yang diperoleh dengan cara mengajukan pertanyaan-pertanyaan secara bertahap ke sumber informan dan dijawab langsung oleh narasumber.

- Dokumentasi

Dokumentasi ini dilakukan untuk memperoleh data melalui bahan-bahan tertulis berupa segala hal yang berkaitan dengan proses produksi amplang.

c. Teknik Pengolahan Data

Teknik pengolahan data yang digunakan dapat bersifat deskriptif kualitatif. Aktivitas dalam analisis data kualitatif dilakukan secara interaktif dan berlangsung secara terus menerus sampai tuntas, sehingga didapatkan data jenuh (Miles dan Huberman dalam Sugiyono, 2014). Metode pengolahan data Miles \& Huberman ditunjukkan pada Gambar 2. 


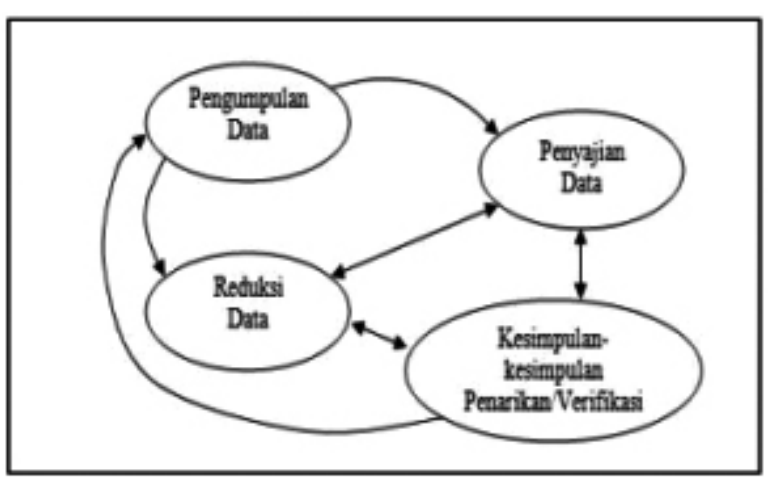

Gambar 2. Metode pengolahan data Miles \& Huberman (Sugiyono, 2014)

\section{- Reduksi Data}

Proses reduksi data diartikan sebagai proses pemilihan, pemusatan perhatian atau penyederhanaan, pengabstrakan, dan transformasi data kasar yang muncul dari catatan lapangan.

- Penyajian Data

Penyajian data merupakan upaya penyusunan sekumpulan informasi ke dalam suatu matrik atau konfigurasi yang mudah dipahami. Dalam penyajiannya, dapat menggunakan matrik, grafik, atau bagan yang dirancang untuk menggabungkan informasi.

- Menarik Simpulan

Data yang diperoleh kemudian dihubungkan dan dibandingkan antara satu dengan yang lainnya sehingga mudah ditarik simpulan sebagai jawaban terhadap setiap permasalahan yang ada.

\section{HASIL DAN PEMBAHASAN}

a. Gambaran Umum SIKHPK

Pembangunan Sentra Industri Kecil Hasil Pertanian Dan Kelautan (SIKHPK) Teritip, Balikpapan berdasarkan Perwali Kota Balikpapan No. 33 Tahun 2018 tentang Pembentukan, Susunan Organisasi, Uraian Tugas dan Fungsi Unit Pelaksana Teknis Daerah Sentra Industri Kecil. SIKHPK berlokasi di Jalan Teritip Laut RT. 8 Kelurahan Teritip Kecamatan Balikpapan Timur. Luas lahan SIKHPK seluas 6,4 hektar. Rumah produksi terbangun pada tahun 2018sebanyak 20 unit yang terdiri dari 7 unit IKM pengolahan hasil pertanian dan 13 unit IKM pengolahan hasil kelautan.

\section{b. Proses Produksi Amplang}

Selain proses produksi, bahan baku juga menjadi aspek penting dalam penentuan mutu produk akhir. Standarisasi bahan baku perlu diperhatikan kususnya untuk bahan baku industri olahan pangan. Standar bahan baku ini meliputi spesifikasi dan persyaratan atau penanganan khusus. Ikan segar yang menjadi syarat bahan baku olahan pangan perlu memiliki kriteria dasar seperti penampakan, bau dan tekstur. Kriteria dasar ini mengacu pada SNI 2729: 2013. Bahan baku ikan segar memiliki karakteristik kenampakan mata cerah dan cemerlang, bau yang segar dan spesifik tergantung dari jenis ikannya, tekstur yang elastik, padat dan kompak. Begitupun, ikan segar yang menjadi bahan baku industri olahan pangan harus berasal dari perairan yang tidak tercemar.

Proses produksi amplang meliputi proses persiapan bahan baku, pencampuran bahan, pencetakan, penggorengan, penirisan, dan pengemasan (Alfisyahrica, 2015). Diagram alir proses produksi amplang ikan ditunjukkan pada Gambar 3. Pada proses pengolahan amplang ikan, ikan yang telah diterima dan telah sesuai dengan syarat mutu bahan baku kemudian dilakukan penyiangan. Penyiangan dilakukan dengan cara memisahkan bagian kepala dan sirip ikan sehingga diperoleh fillet ikan. Fillet kemudian dicuci menggunakan air bersih untuk menghindari kontaminasi dari bakteri pembusuk, serta kepala dan sirip ditempatkan pada wadah terpisah agar tidak tercampur dengan fillet ikan yang diperoleh sebab kepala dan sirip juga merupakan sumber kontaminan pada proses produksi amplang ikan. Setelah fillet ikan bersih dari sumber kontaminan, ikan disimpan dalam freezer pada suhu $0-5^{\circ} \mathrm{C}$ dengan pemberian kode bahan yang mewakili waktu bahan dilakukan penyimpanan. 


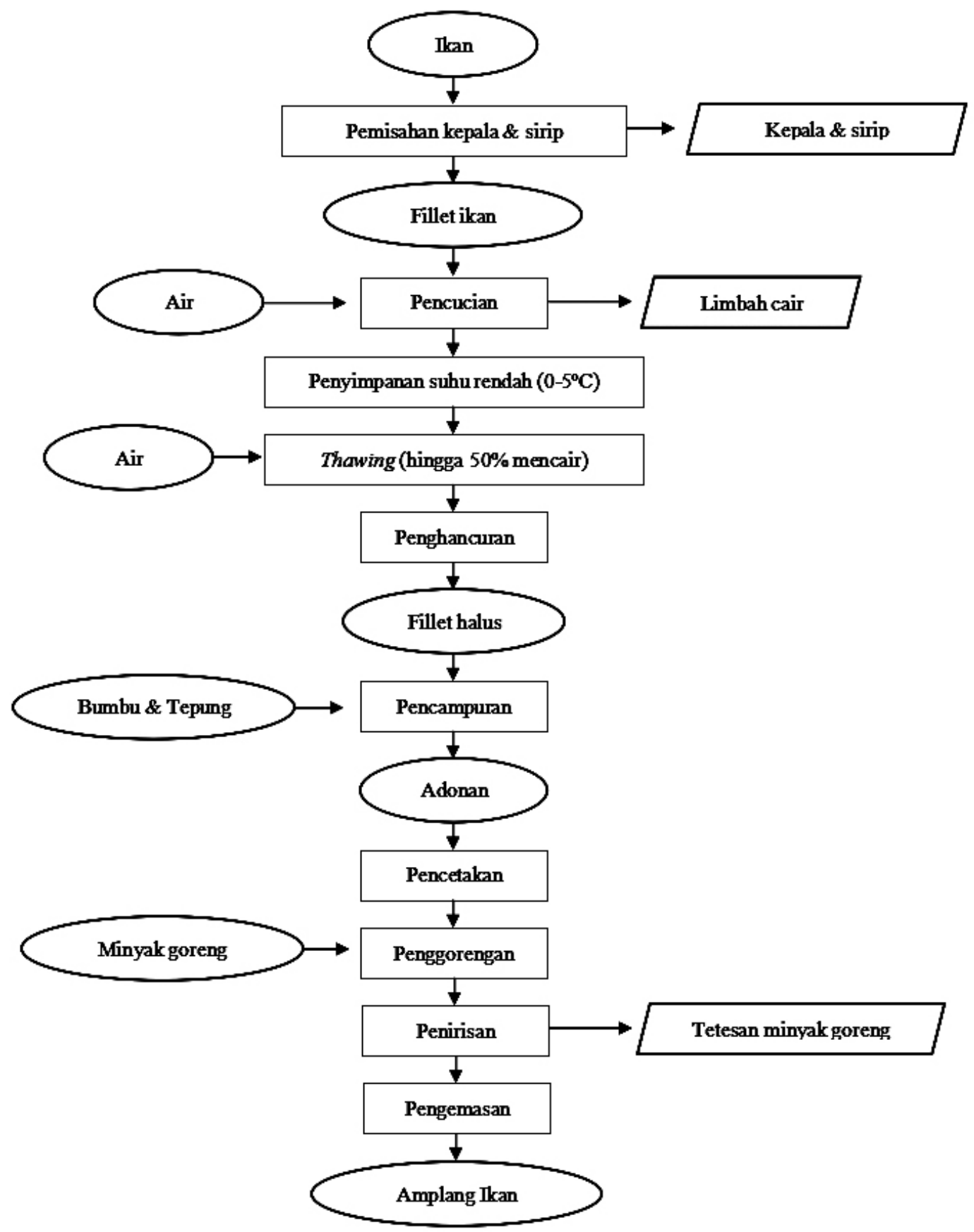

Gambar 3. Diagram alir proses produksi amplang ikan

Pengkodean bahan yang disimpan di dalam freezer bertujuan untuk mengatur keluar masuknya bahan sehingga menerapkan sistem first in first out. Yang dimaksud adalah pada proses penyimpanan baku, diharapkan bahan yang pertama kali masuk ke dalam freezer akan digunakan sebagai bahan baku produksi pertama kali (pertama kali keluar dari freezer) sehingga tidak ada penumpukan bahan baku yang telah lama disimpan di freezer. Proses selanjutnya yaitu penghalusan bahan baku (fillet ikan). Setelah dihaluskan, daging ikan dicampur dengan bahan tambahan seperti bumbu dan tepung. Penambahan tepung dilakukan sedikit demi sedikit agar adonan merata dan dicampur hingga adonan kalis. Selanjutnya adonan tersebut dicetak sesuai yang diinginkan dan kemudian digoreng pada wajan yang berisi minyak yang telah panas. Setelah itu, amplang yang telah digoreng ditiriskan 
menggunakan mesin peniris hingga minyak goreng terpisah. Setelah minyak terpisah dari amplang dan amplang dirasa cukup dingin, selanjutnya amplang dilakukan pengemasan dengan menggunakan kemasan PP dan labeling.

\section{c. SOP Proses Produksi Amplang}

SOP atau prosedur merupakan dokumen dibuat secara jelas dan rinci untuk menjelaskan metode yang digunakan dalam mengimplementasikan dan melaksanakan kebijakan dan aktivitas organisasi seperti yang telah ditetapkan dalam pedoman. Menurut Soemohadiwidjojo dalam Irawati dan
Hardiastuti (2016), pada dasarnya prosedur merupakan instruksi tertulis sebagai pedoman dalam menyelesaikan sebuah tugas rutin atau tugas yang berulang (repetitif) dengan cara yang efektif dan efisien, untuk menghindari terjadinya variasi atau penyimpangan yang dapat mempengaruhi kinerja perusahaan secara keseluruhan. Untuk itu, SOP proses produksi amplang sirancang untuk menghasilkan amplang yang seragam baik mutu dan bentuknya, serta sesuai dengan persyaratan mutu amplang yaitu SNI 7762: 2013. SOP proses produksi amplang ikan ditunjukkan pada Gambar 4.

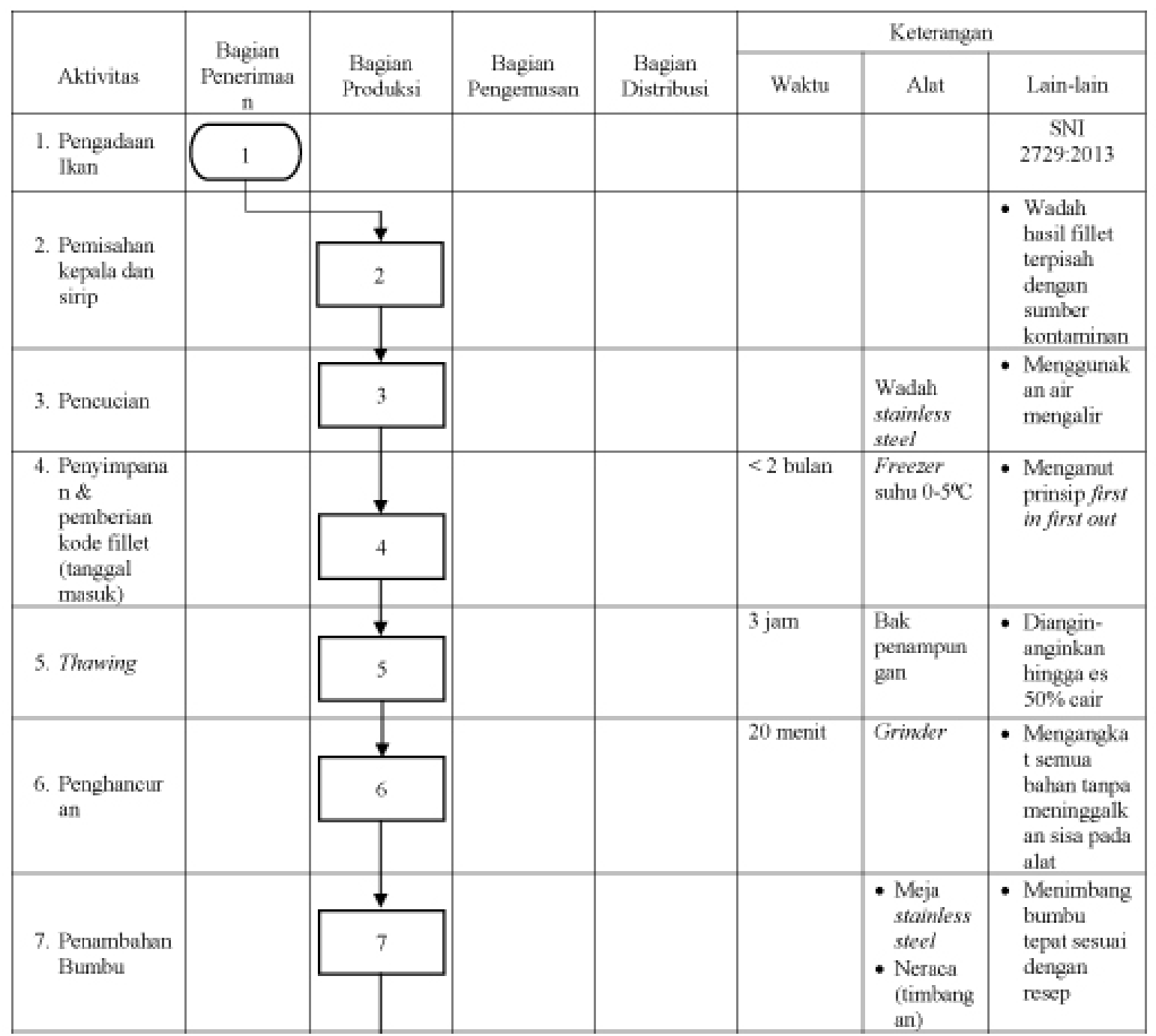




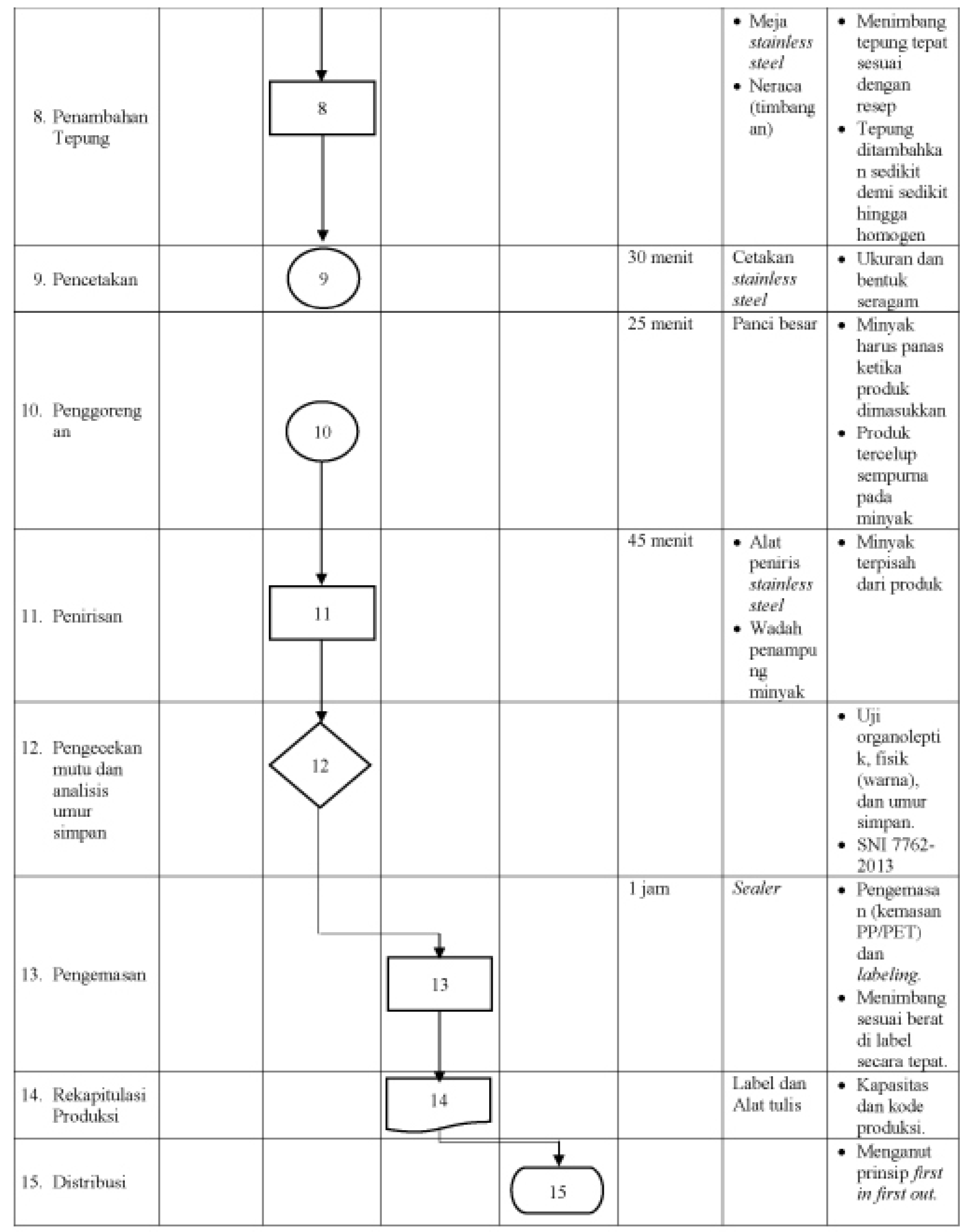

Gambar 4. SOP proses produksi amplang ikan 
Proses produksi pengolahan amplang dibagi menjadi beberapa bagian, yaitu bagian penerimaan bahan, bagian produksi, bagian pengemasan, dan bagian distribusi. Bagian penerimaan bahan betugas di lokasi gudang penyimpanan bahan baku, bagian produksi meliputi kepala produksi dan empat karyawan, bagian pengemasan sebanyak empat karyawan, dan yang terakhir bagian pemasaran sebanyak satu karyawan. Kepala produksi mengatur dan mengawasi proses produksi dan pengemasan sehingga produk siap untuk dipasarkan.

\section{KESIMPULAN}

Dari hasil dan pembahasan, dapat diambil kesimpulan bahwa rancangan SOP proses produksi amplang ikan telah tersusun dalam bentuk swimlane flowchart dan naratif, dengan unit proses meliputi unit penerimaan bahan baku, unit produksi, unit pengemasan, dan unit pemasaran. Pada unit produksi dan unit pengemasan dipimpin oleh satu kepala dapur yang bertanggungjawab atas proses produksi ampang ikan.

\section{UCAPAN TERIMA KASIH}

Ucapan terima kasih ditujukan kepada Kementerian Perindustrian Republik Indonesia yang telah yang mendukung secara finansial terlaksananya penelitian yang berjudul Penyusunan Proses Bisnis Sentra Industri Kecil Hasil Pertanian dan Kelautan (SIKHPK) Teritip.

\section{DAFTAR PUSTAKA}

Afifah, C.A.N. 2016. Penggunaan jumlah Tapioka dan Soda Kue terhadap hasil jadi Amplang Ikan Lele (Clarias Sp.). e-journal Boga (5): 265-273

Alfisyahrica. 2015. Variasi bagian Telur dan presentasenya dengan Daging Ikan pada proses pengolahan Amplang Ikan Lele Dumbo (Clarias gariepinus) (Skripsi). Jember, Fakultas Teknologi Pertanian,
Universitas Jember.

Badan Standarisasi Nasional (BSN). $2013 a$. Amplang Ikan: SNI 7762:2013. Jakarta, Badan Standarisasi Nasional.

Badan Standarisasi Nasional (BSN). 2013b. Ikan Segar: SNI 2729:2013. Jakarta, Badan Standarisasi Nasional.

Dongoran, F.R., Nisa, K., Sihombing, M., \& Purba, L.D. 2016. Analisis jumlah pengangguran dan ketenagakerjaan terhadap keberadaan usaha mikro kecil dan menengah di kota Medan. Jurnal EduTech (2): 59-72

Hendini, A. 2016. Pemodelan UML sistem informasi monitoring penjualan dan stok barang (studi kasus: distro zhezha pontianak). Jurnal Khatulistiwa Informatika (4): 107-116

Irawati, R., \& Hardiastuti, E.B.W. 2016. Perancangan standard operating procedure (SOP) proses pembelian Bahan Baku, proses produksi dan pengemasan pada industri jasa boga (studi kasus pada PT. KSM catering \& bakery batam). Jurnal Akuntansi, Ekonomi dan Manajemen Bisnis (4): 186-193

Kementerian Perindustrian Republik Indonesia, 2016. Peraturan menteri perindustrian republik indonesia nomor o9/M-IND/ PER/2/2016 tentang petunjuk teknis penggunaan dana alokasi khusus bidang pembangunan sarana industri tahun anggaran 2016. Jakarta, Kementerian Perindustrian Republik Indonesia.

Sugiyono. 2014. Metode penelitian manajemen. Bandung, Alfabeta.

Tambunan, R.M. 2011. Panduan penyusunan standard operating procedure (your best guidance to have effective standard operating procesure). Jakarta, Maiestas Publishing. 